\title{
A PARTICIPAÇÃO DA ENFERMEIRA NA CAMPANHA DE ERRADICAÇÃO DA VARÍOLA NO ESTADO DE SÃO PAULO NO PERÍODO 1968-1973a
}

\author{
The Participation of Nurses on the Variola Extermination \\ Campaign in the State of São Paulo, Brazil, during 1968-1973 \\ Participacíon de la Enfermera en la Campaña de Erradicación de \\ la Viruela en el Estado de São Paulo, Brasil, en el Período 1968-1973
}

Aildnize Geselli Santos

Maria Cristina Sanna

\begin{abstract}
Resumo
A Campanha da Erradicação da Varíola (CEV) foi um movimento conduzido pela Organização Mundial de Saúde a partir de 1965, com o objetivo de erradicar a doença no mundo. No Brasil, ela foi coordenada pelo Ministério da Saúde, porém descentralizada em alguns estados, como no Estado de São Paulo. A incidência neste estado era alta, o que desper tou o brio dos sanitaristas para a obtenção rápida de resultados. Para tanto, montou-se uma coordenação ligada ao secretário estadual da saúde, integrada por vários profissionais, dentre os quais a enfermeira. 0 presente trabalho objetiva descrever e analisar a participação dessas enfermeiras na CEV no Estado de São Paulo. Neste estudo de caráter histórico-social, que emprega documentos escritos oficiais da campanha, produzidos no período de 1968 a 1973, encontrou-se comprovação do envolvimento das enfermeiras no treinamento de vacinadores, na determinação de estratégias de cobertura da população e na coordenação da logística da campanha.
\end{abstract}

Palavras-chave: História. Enfermagem. Campanhas de Vacinação. Imunização. Varíola.

\begin{abstract}
The Smallpox Extermination Campaign (CEV) was a movement conducted by the World Health Organization in 1965, with the objective of exterminates smallpox in the world. In Brazil, it was coordinated by the Minister of Health, which caused decentralization in some states, like São Paulo. The occurrence in this state was high, and this fact awoke the sanitarians' interest in obtain fast results. To conquer this objective, a committee was formed, linked to the state's health secretary, integrated with various professionals, including nurses. This study of a social-historic nature, that uses official documents, written between 1968 and 1973, reveals confirmation of the nurses' involvement in the training vaccinator programs, defining strategy of cover population and logistic coordination of the campaign.
\end{abstract}

\section{Resumen}

La Campaña de Erradicación de la Viruela (CEV) fué un movimiento conducido por la Organización Mundial de la Salud desde 1965, con el objetivo de erradicar la enfermedad en el mundo. En Brasil, fue coordinada por el Ministerio de la Salud, pero descentralizada en algunos estados, como en el Estado de São Paulo. La incidencia, en este estado era alta, lo que despertó el interés de los sanitaristas para obtener resultados de una forma más rápida. Para esto se formó una organización unida al secretario estadual de la salud, integrada por varios profesionales y uno de ellos eran enfermeras. En este estudio de carácter histórico social, que emplea documentos escritos oficiales de la campaña, producidos en el periodo de 1968 hasta 1973, se encontró comprobación del envolvimiento de las enfermeras en el entrenamiento de vacunadores, determinación de estrategia de cobertura de la población y coordinación de logística de la campaña.
Keywords:History. Nursing. Mass Immunization. Immunization. Variola.
Palabras clave: Historia. Enfermería. Inmunización Masiva. Inmunización. Viruela. 


\section{INTRODUÇÃO}

A história da varíola é conhecida desde os primórdios da humanidade. Até sua plena erradicação, a varíola ocupou lugar de expressão no quadro epidemiológico mundial, se difundido indiscriminada e violentamente, dizimando populações ao longo dos séculos e deixando marcas físicas e sociais ${ }^{1}$.

Denomina-se varíola a moléstia aguda causada por Poxvírus variolae, um vírus específico pertencente ao grupo de vírus orthopoxvírus ("grupo varíola-vacínia"), de características definidas. A varíola é um protótipo das infecções exantemáticas. Na época em que se localiza este estudo, a doença ocorria sob duas formas distintas, epidemiológica e clinicamente caracterizadas, no Brasil denominadas: "Alastrim", que correspondia à varíola minor ou, hoje denominada varicela, e a "verdadeira", correspondente à forma major, que foi erradicada no mundo?

0 vírus da varíola é um dos mais resistentes, em particular aos agentes físicos. Crostas de lesão abandonadas por mais de um ano à temperatura ambiente conservam a infectividade ${ }^{(2)}$, e o vírus é transmitido geralmente por contato físico íntimo e através de contato com secreções das vias respiratórias e lesões da pele e mucosas doentes, bem como por objetos recém-contaminados. Tem o homem como único reservatório e um período de incubação de 7 a 8 dias, causando cefaléia, aparecimento de exantema, toxemia e hipertermia ?

As características observadas na disseminação da varíola fazem com que o controle de uma epidemia seja relativamente mais fácil do que em outras doenças contagiosas. Isso gerou, precisamente, a oposição à vacinação em massa de populações, limitando a vacinação aos "anéis expansivos", isolamento dos casos e vigilância sanitária dos contatos. Cada "anel expansivo" ou "barreira" consistiu-se em contatos com um determinado grau de convivência pessoal com infectante 2 .

A vacina antivariólica consistia numa suspensão de tecidos animais, geralmente pele de vitela ou membrana corioalantóide de embrião, contendo o vírus ativo ("vivo") da vacina. Esse vírus, Poxvirus officinale, é mutante, obtido no laboratório, pela passagem seriada do vírus da vaca (Cowpox) ou, ainda, do vírus da varíola humana, em pele de vitela e de coelho. Para alguns autores, o vírus da vacínia e o da varíola da vaca são idênticos².

A história da vacinação antivariólica foi muito conturbada em todo mundo. Começou com a técnica utilizada na corte portuguesa, com a vacinação braçoa-braço; porém, em virtude da pequena produção da vacina animal (Cowpox), a técnica também incluía o comparecimento dos vacinados após oito dias (quintafeira ou domingo seguintes àqueles em que foram vacinados) para que o pus fosse extraído de sua pústula e utilizado na vacinação de outras pessoas. Muitos vacinados resistiam a esse retorno demorado e incômodo, o que provocava uma constante "queda-de-braço" (daí a origem da expressão) entre os populares e os vacinadores, esses últimos freqüentemente apoiados pela autoridade policial $^{3}$. Essas situações repercutiram no Brasil e comprometeram a propagação dos serviços de vacinação.

Além disso, havia controvérsia entre os próprios médicos sobre a eficácia da vacina, haja vista a existência de casos de varíola entre os vacinados, que alguns médicos explicavam pelo enfraquecimento da linfa vacínica, na transferência braço-a-braço, e a confusão com outras doenças, como a varicela ou catapora ${ }^{(3,4)}$.

Em 1846, a vacinação tornou-se obrigatória em todos os municípios do país, pelo Decreto Imperial $n^{\circ} 464$, mas as dificuldades encontradas inviabilizaram sua implantação. A técnica da vacina animal, que dava origem à linfa vacínica, foi introduzida no país somente em $1887^{3}$.

A vacina antivariólica tornou-se compulsória no Estado de São Paulo em 1891, resultado da segunda lei estadual de saúde, aprovada dez dias depois da organização do Serviço Sanitário no Estado. Apesar da obrigatoriedade e de, no começo, não ter causado conflitos, como acontecia no Rio de Janeiro, uma década mais tarde ela desencadeou uma acirrada polêmica em torno dos limites entre "0 respeito às liberdades individuais e as prerrogativas do Estado em Saúde Pública" ${ }^{3}$.

A evolução tecnológica propiciou o desenvolvimento de preparado vacinal aplicado por técnica de multipuntura, que veio substituir a vacinação primitiva.

A varíola e a vacinação antivariólica, as primeiras campanhas de vacinação em massa, sua forma de organização e as reações populares são elementos históricos importantes para o resgate do impacto que esta nova forma de trabalhar com saúde causou: a prevenção mediante utilização de imunobiológicos ${ }^{3}$.

Na década de sessenta do século XX, na CEV, a vacina antivariólica utilizada foi a liofilizada, diluída e aplicada com o Ped-0-Jet, concomitante à técnica de multipuntura.

A CEV, no Estado de São Paulo, foi criada por orientação da Organização Mundial de Saúde (OMS) que, na XVI Assembléia Mundial da Saúde de 1965, decidiu pela erradicação da varíola como uma das metas principais para o período. Coordenando os esforços do governo federal e da Organização Pan-Americana da Saúde (OPAS), o governo do Estado de São Paulo criou, na Secretaria de Estado de Saúde, por força do Decreto $n^{0}$. 49021, de 30 de novembro de 1967, a CEV do Estado de São Paulo, com o objetivo de erradicar a doença ${ }^{5}$. 
0 Estado de São Paulo, que mantinha uma atitude de independência em relação às prescrições de origem nacionais, apresentava condições favoráveis para integrar os serviços de saúde pública porque possuía a mais vasta rede sanitária do país, contando com recursos humanos, financeiros e materiais, pois detinha o maior potencial econômico da nação.

$\mathrm{Na}$ década de 1960, apesar da Ditadura Militar, o Estado nacional era dividido em blocos econômicos; São Paulo estava forte estruturalmente, a política estava centralizada, e as outras estruturas de outros Estados encontravam-se abaladas. São Paulo foi o berço da resistência da elite sulista (região sul), tendo um cunho democrático, que era combatido pela força policial, 0 que levava, assim, a população a várias revoltas. Essa força político-econômica garantia independência ao Estado de São Paulo, tornando-o pioneiro nas iniciativas de ações programáticas de saúde.

Um marco emblemático dessa luta pelo poder e autonomia deu-se em 18 de setembro de 1973, quando foi criado o Programa Nacional de Imunização (PNI), com a finalidade de atender à prioridade no discurso do governo brasileiro: o redirecionamento no setor de vacinação. Coincidentemente, nesse mesmo ano, deu-se o fim das campanhas de vacinação contra varíola no Estado de São Paulo. Esse programa teve como objetivo a promoção do controle do sarampo, tuberculose, difteria, tétano, coqueluche e poliomielite, e a manutenção da situação de erradicação da varíola. 0 programa ficou sob a coordenação de uma comissão, composta por representantes do Ministério da Saúde, da OPAS e da Central de Medicamentos (CEME), com a liderança da Fundação de Serviços de Saúde Pública (FSESP) ${ }^{6}$.

São Paulo foi o pioneiro em campanhas de imunização. Das diferenças existentes entre os paradigmas adotados no Estado de São Paulo e na União, que, após a CEV, propôs planos nacionais de vacinação, abriu-se outro foco de resistência, quando São Paulo manteve, até 1984, um calendário próprio de vacinação, diferente do nacional.

A Enfermagem, durante a história da varíola, teve a sua atuação anotada desde 1928, pois participou no tratamento e na vigilância de doentes atingidos por um surto de febre amarela, conseguindo, em quatro meses, a rápida baixa de casos. Epidemias e surtos de varíola, sarampo, febre tifóide e outras doenças infecto-contagiosas foram rapidamente extintas, graças à ação dessas a que chamavam "as mensageiras da saúde" 7 .

Os primeiros casos de varíola no Brasil chegaram em 1804 e, em São Paulo, em 1891: um caso importado da África ${ }^{8}$. No entanto, pelos documentos da CEV, constatase que esta foi a primeira vez que a Enfermagem paulista teve participação reconhecida em uma campanha de grande âmbito. 0 Brasil, nas décadas de 1960 e 1970 foi o foco da varíola na América Latina, pois, no ano de 1969, foram notificados 7.407 casos por todo o país, dois quais 1.395 (18\%) pertenciam a São Paulo.

Considerando este cenário, a escolha do tema da presente pesquisa se deu pela necessidade de estudar e compreender qual foi o papel realmente desempenhado pelas enfermeiras durante a CEV e evidenciar como a Enfermagem administrou a campanha de vacinação antivariólica no Estado de São Paulo.

\section{OBJ ETIVOS}

Descrever e analisar a participação da enfermeira na CEV no Estado de São Paulo.

\section{METODOLOGIA}

A presente investigação consiste em um estudo exploratório descritivo, de caráter histórico-social, proporcionado por um levantamento bibliográfico e documental realizado em fontes escritas referentes à atuação e participação da enfermeira durante a Campanha de Erradicação da Varíola no Estado de São Paulo.

Primeiramente foi realizado um levantamento bibliográfico, com recursos eletrônicos, nos seguintes bancos de dados: LILACS (Literatura Latino-Americana e do Caribe), BDENF (Banco de Dados de Enfermagem da Biblioteca Virtual em Saúde), HISA (História sobre a Saúde) e PERIENF (Periódicos de Enfermagem do Acervo da Escola de Enfermagem da USP em Língua Portuguesa). Para tanto, utilizaram-se as palavraschave: Enfermagem, Campanha, História, Imunização, e, apesar de se terem encontrado publicações sobre o tema, nenhuma delas era referente ao objeto de estudo da presente indagação, focado na Enfermagem.

Em seguida iniciou-se um levantamento de documentos escritos, que ainda não receberam um tratamento analítico por profissional da área de arquivística e museologia, compostos principalmente por relatórios administrativos, apostilas de treinamentos e outros materiais didáticos do Museu de Saúde Pública Emílio Ribas (MUSPER) , onde esses documentos ainda não estão sequer catalogados.

A próxima etapa consistiu na identificação das fontes citadas e obtenção da reprodução do material por meio eletrônico, quando autorizado, e cópia manual, quando não autorizado, providenciando-se certificação de autenticidade dos documentos.

De posse do material, foi realizada uma leitura compreensiva dos documentos e foram feitos 0 
fichamento dos pontos principais e a aglutinação por pertinência temática, sucedida por uma revisão dos documentos escritos encontrados, em função dos objetivos em pauta, de forma a permitir a identificação das distribuições dos registros da CEV, destacando o Programa de Enfermagem e a sua atuação na Saúde Pública do Estado de São Paulo, apresentando-se, a seguir, os resultados obtidos.

\section{RESULTADOS E DISCUSSÃO}

A vacinação antivariólica foi o primeiro processo de operação sanitária em massa concebido e dirigido pelo Estado. Não que a vacinação antivariólica não tivesse desempenhado papel de destaque em momentos anteriores. Como explicaram Teixeira e Almeida ${ }^{9}, \ldots$ com o advento da República, deu-se a organização do Serviço Sanitário do Estado de São Paulo; [e] nesta fase, a criação do Instituto Vacinogênico de São Paulo foi um marco no desenvolvimento das atividades vinculadas ao combate à varíola. Isto comprova que já havia interesse no controle da doença antes da decisão pela CEV, porém, a jornada dos anos 60 e 70 do século $X X$ foi dirigida à sua erradicação.

A CEV desenvolveu-se em três fases: Ataque, Consolidação e Manutenção. Cada fase teve suas particularidades e atuações diferenciadas das enfermeiras, como se descreverá, com a indicação dos atores com quem elas interagiam e o que com elas realizaram. Para apresentação dos resultados serão empregadas essas mesmas etapas como eixo descritor.

0 FESIMA (Fundo de Educação Sanitária e Imunização em Massa Contra as Doenças Transmissíveis) foi instituído pela lei $n$. 10.108 de 8 de maio de 1968, posteriormente transformado em fomento, conforme o decreto n. 52.639 de 3 de fevereiro de 1971. Era vinculado diretamente à Secretaria Estadual da Saúde e tinha, como objetivo, custear, com seus recursos orçamentários, os programas de imunização em massa da Secretaria ${ }^{10}$.

De acordo com o disposto do Artigo $2^{\circ}$ do Decreto $\mathrm{n}$. 49.021 de 30 de novembro de 1967, a Coordenadoria da CEV era um órgão diretamente subordinado ao secretário do Estado de São Paulo, mas, paralelamente havia as sessões técnicas, compostas por estatísticos e epidemiologistas, educadores em saúde, enfermeiros, diretores e colaboradores dos serviços locais, mais corpo médico categorizado em: avaliador, supervisor e chefe de equipe e, finalmente, vacinadores e motoristas.

A vacinação em massa da população de todos os municípios do Estado, isto é, o trabalho de campo, foi realizada pelas equipes de vacinação.

0 resultado total da vacinação antivariólica sistemática, realizada na fase de ataque, iniciada no dia
5 de agosto de 1968 e que teve seu término no dia 5 de agosto de 1970, apurou 15.742 .061 pessoas vacinadas, representando 90,7\% do Estado de São Paulo.

A vacinação sistemática foi realizada mecanicamente por meio do Ped-0-Jet, que alcançou 11.019.439 pessoas, cerca de $70 \%$ da população vacinada, e manualmente por meio da multipuntura, praticada com agulha bifurcada, feita casa a casa, empregada na zona rural e nas operações de rastreio, atingindo 4.722 .622 pessoas ou $30 \%$ da população vacinada ${ }^{11}$.

Verificou-se discordância de datas na fase de ataque, pois, na página cinco do Relatório Final de Atividades do ano de 1970, assinado por Rui Soares, consta que essa fase teve seu início no dia 5 de agosto de 1968 e seu término no dia 31 de agosto de 1970. Já na página sete, ele se contradiz, apontando a data do término dessa fase como dia 31 de dezembro de 1970. Esta discrepância de datas pode ser um indicativo de que o relatório citado não foi originalmente escrito por quem o assinou, ou que o controle das fases não ficou a cargo desse nível de comando.

A Enfermagem, na fase de ataque, ficou responsável pelo treinamento do pessoal na técnica de multipuntura, em cursos programados, a fim de satisfazer as exigências de vacinar pelo menos $90 \%$ da população do Estado. Devido ao conhecimento sobre a falta de higiene da maioria dos vacinadores declarada pelas enfermeiras, estas se restringiram ao ensino da técnica de vacinação, pois houve também a necessidade de abranger ensinamentos sobre higiene individual.

Estes cursos, no total de cinco, foram realizados para 19 supervisores e 19 avaliadores, e houve mais quatro cursos para 610 vacinadores. 0 total de pessoas treinadas foi 648 , segundo o relatório da campanha intitulado "Enfermagem na CEV"12. A Enfermagem ainda se responsabilizou pela supervisão, no campo de trabalho, do pessoal por ela treinado, na técnica da multipuntura.

Em razão da deficiência do pessoal que pudesse atender a todas as investigações epidemiológicas das notificações de varíola provenientes das Unidades Sanitárias, para complementação dos serviços, a Enfermagem da CEV foi solicitada para colaborar nesse trabalho, aproveitando a oportunidade para treinar pequenos grupos de vacinadores que realizavam 0 bloqueio em todos os casos investigados. Os funcionários das unidades sanitárias pertencentes ao município no qual faziam as investigações dos casos notificados foram: 4 de Mauá, 42 no grande ABC (Santo André, São Bernardo e São Caetano), 3 em Diadema, totalizando 49 funcionários.

A Enfermagem, nesta fase, não ficou só no treinamento para vacinadores, mas também no levantamento da população, com apoio do 
Departamento de Estatística da Secretaria de Economia e Planejamento do Estado, para estimar a demanda da população e distribuir o pessoal por ela treinado.

Nos locais de vacinação, a Enfermagem teve atitudes estratégicas de escolher locais onde havia um grande número de pessoas, como escolas e feiras livres. Nas unidades sanitárias da capital, ministrou treinamentos intensivos na técnica de vacinação por multipuntura, ao pessoal auxiliar das sedes dos Distritos Sanitários.

A fase de Consolidação, ou fase II, em escala estadual, teve seu início no dia primeiro de setembro de 1970. Seguiu paralelamente junto com a fase de ataque, mantendo continuamente 0 alto nível de imunidade da população, evitando a propagação da varíola.

Segundo Soares ${ }^{13}$, a Coordenação da CEV, nesta fase, considerando as dificuldades da organização, a deficiente capacitação técnica do pessoal auxiliar e a falta de recursos materiais, propôs-se a auxiliar as unidades de saúde, na medida de seus recursos e possibilidades, colocando à sua disposição as enfermeiras da CEV para treinar o pessoal auxiliar, das unidades, na técnica de vacinação antivariólica pelo método de multipuntura.

Soares ${ }^{13}$ ainda refere que de acordo com as informações colhidas na publicação da enfermeira Yolanda Sanson e outras seis autoras, esta participação correspondeu ao período de outubro de 1968 a maio de 1970. Foi realizada em 132 municípios do interior do estado, no qual se localizavam 449 unidades sanitárias e outras instituições. Foram treinados 1.305 servidores componentes das unidades sanitárias e 36 de outras instituições, arrolados entre as categorias de fiscais sanitários.

0 treinamento do pessoal auxiliar na capital abrangeu 44 centros de saúde, 108 postos de puericultura, 48 unidades sanitárias pertencentes ao Departamento de Assistência à Maternidade e à Infância, uma pertencente à Assistência Escolar da Prefeitura e três outras instituições não identificadas. Destas instituições, foram treinados 764 servidores, entre os selecionados, os quais pertenciam às categorias de fiscal sanitário, atendente e servente.

As enfermeiras da CEV, em seu programa de treinamento do pessoal auxiliar das unidades sanitárias, organizavam, também, uma rede de notificantes sanitários, tendo um único Centro Receptor Principal das notificações da unidade sanitária ${ }^{13}$.

A Enfermagem passou a desenvolver atividades com as diferentes Divisões Regionais de Saúde, com o propósito de realizar a fase experimental da consolidação, cujo programa constou basicamente de treinamentos, que tinham como base a técnica da multipuntura para vacinação de $90 \%$ dos nascidos vivos no Estado, durante 0 ano, vacinação dos escolares sem cicatriz vacinal, instalação e controle de postos de notificação, investigação epidemiológica dos bloqueios dos casos notificados, técnica e coleta de material para exame laboratorial e campanhas de vacinação básica e reforço das vacinas Tríplice, Dupla, Sabin, Anti-sarampo e Antitetânica.

Em virtude da reforma administrativa ocorrida na Secretaria da Saúde, presumivelmente em 1971, quando se iniciou a segunda fase da CEV, foi exigida a destinação exclusiva das enfermeiras para este fim, já que passaram a trabalhar em nível nacional, ficando apenas uma no Estado de São Paulo e as outras seis divididas pelo restante do país.

$\mathrm{Na}$ fase definitiva da consolidação, o treinamento do pessoal auxiliar das unidades sanitárias, antes feito pelas enfermeiras, passou a ser responsabilidade dos inspetores de epidemiologia e vacinadores da CEV, previamente preparados pelas enfermeiras.

Todo pessoal da CEV ficou administrativamente subordinado à Diretoria das Divisões Regionais e era tecnicamente supervisionado pelas respectivas chefias de enfermagem. Às enfermeiras da CEV também coube a assessoria técnica de todo Estado de São Paulo, e elas agiam em caráter supletivo, executivamente, onde se fizessem necessárias.

A fase de manutenção em escala estadual teve seu início em primeiro de setembro de 1973. Esta fase compreendeu: vacinação de $90 \%$ das crianças nascidas no ano de 1973 e vacinação de $100 \%$ dos escolares de todos os níveis que não apresentavam cicatriz da vacina.

A Enfermagem dirigiu seu trabalho para a manutenção e vigilância epidemiológica da varíola, tendo como objetivo manter a doença erradicada em todo 0 território do Estado de São Paulo, o que foi alcançado.

Para tanto, organizou e estruturou o sistema de notificação em todos os municípios do Estado de São Paulo com a participação da comunidade, realizou investigação epidemiológica de todos os casos suspeitos, orientou o pessoal necessário para execução do Plano de Trabalho, mediante treinamento em serviço e supervisão continua, e orientou membros da comunidade na integração do Sistema de Vigilância, através dos postos de notificação subsidiários.

Essas metas só foram alcançadas porque a Enfermagem adotou algumas estratégias: A) orientação e treinamento do pessoal e recursos da comunidade, prestando esclarecimentos em relação à importância da descoberta e notificação de casos suspeitos de varíola; B) instalação, dinamização e supervisição dos postos de notificação subsidiários; C) realização da supervisão e orientação de 
investigação epidemiológica de casos suspeitos de varíola; D) realização de fechamento de casos, pesquisa de fontes de infecção e levantamento de comunicantes de casos suspeitos de varíla nas regionais; e E) realização de encaminhamento de inquéritos epidemiológicos de casos de varíola para a OMS e para a Fundação IBGE (Instituto Brasileiro de Geografia e Estatística) ${ }^{14}$.

Além dessas atividades, a equipe de enfermeiras fez a coordenação, planejamento e treinamento para o cadastramento de crianças de 0-6 anos de idade em municípios com mais de trinta mil habitantes.

Estimativas de população para o ano de 1973, área e densidade demográfica de todos os municípios pertencentes às Regionais de Saúde, dimensionamento de pessoal - inspetores de epidemiologia e atendentes de distrito, participação em reuniões da Coordenadoria de Saúde da Comunidade, das divisões regionais da CEV, elaboração de roteiros de natureza desconhecida, programas de trabalho, relatórios mensais de atividade da CEV, supervisão da conservação de vacina antivariólica, juntamente com a Coordenadoria de Serviços Técnicos especializados do Instituto Butantã, foram outras de suas atividades.

0 regaste histórico da atuação das enfermeiras da CEV serve para situar historicamente as enfermeiras e alertá-las sobre a importância de fazer parte do planejamento e execução, mas jamais esquecer de avaliar os dados colhidos, para que a nossa história não se transforme em fumaça. Somente assim, daremos o real valor à nossa profissão e à nossa história.

Este estudo é a primeira aproximação do tema, e a exploração do material coletado não termina aqui. Várias abordagens poderiam ter sido adotadas como possibilidade de análise: A História do Conhecimento sobre a doença, quando seriam tratados o contágio, o tratamento e prevenção ao longo do tempo; a História Social da doença, quando as ações e reações da sociedade perante a doença seriam o foco de interesse; ainda poder-se-ia resgatar a História Política, verificando a extensão das políticas públicas e a resposta social a elas, como já fizeram outros autores; e, finalmente, poder-se-ia escrever sobre a História das Mentalidades, voltando o olhar para a representação social da doença. Como este foi um trabalho de conclusão de curso de Graduação em Enfermagem, diante do reduzido tempo disponível, optou-se por acrescentar conhecimento sobre Administração em Enfermagem, um campo que ainda é carente de estudos voltados para este saber-fazer.

A esse propósito, registre-se que o trabalho do enfermeiro possui várias facetas, dentre as quais a assistencial é a mais visível, ainda que haja alguma ambigüidade quando se analisa a divisão do trabalho entre este profissional e os demais elementos da equipe de enfermagem. Já a dimensão gerencial, que compreende a organização do trabalho assistencial de enfermagem, é pouco estudada e relatada, embora seu desempenho esteja presente desde antes da implantação do modelo nightingaleano, e mais ainda após este fenômeno. Por este motivo, compreender como este fazer vem se dando no percurso histórico da construção do conhecimento em Enfermagem é relevante, e nada melhor que estudá-lo numa situação de atenção à saúde em que o saber a esse respeito foi solicitado e produziu efeitos que podem explicar como operava o Administrar em Enfermagem à época.

Lembre-se, ainda, que a CEV ocorreu no momento em que a organização da assistência à saúde amplamente entendida passou exigir cada vez mais o emprego da ciência da Administração, o que remeteu ao aproveitamento das competências que os enfermeiros já possuíam, posto que este era o único profissional de saúde que contava, no percurso de sua formação, com a inclusão de conteúdos e práticas voltadas para esse fazer.

Pode-se perceber que ainda há muito que descobrir sobre o tema em pauta, e pretende-se ampliar a investigação com entrevistas e documentos particulares das enfermeiras que atuaram na CEV e trazer novas informações e perspectivas sobre sua participação nesse importante acontecimento da História da Saúde no Brasil.

\section{CONCLUSÃO}

É um fato bem evidente que a Enfermagem foi além do treinamento durante a CEV. Além de treinamentos, a Enfermagem se ocupou com toda a comunidade. A enfermeira fez recrutamentos, deu instrução e treinamento da maioria das pessoas que participaram da CEV, organizou o suporte logístico da campanha, propôs a estrutura organizacional da Coordenadoria e instituiu os procedimentos de vigilância epidemiológica.

Devido à complexidade da CEV, a princípio, a Enfermagem era representada somente por uma enfermeira. Esta teve que fazer o levantamento de população, planejar áreas para vacinação e todos os registros administrativos da CEV. Vendo a importância do trabalho da enfermeira e o grande sucesso da CEV, foram contratadas, na fase experimental de consolidação, mais três enfermeiras para auxiliar no restante da campanha.

A supervisão foi atuante durante todas as fases da Campanha.

A vacinação, por ser obrigatória em todo o Estado, causava revolta na população, brigas e desconforto 
dos profissionais, e, por isso, a Enfermagem, junto à população, fazia um trabalho de convencimento, ministrando palestras de esclarecimento quanto à importância da vacinação.

As vacinações em massa eram todas organizadas pelas enfermeiras, que planejavam a quantidade de vacinas, a conservação, todo o material utilizado e também a distribuição e supervisão de recursos humanos.

A Enfermagem tinha toda parte operacional sob seu comando. Como ação de controle, implantou um sistema de investigação epidemiológica para facilitar o levantamento dos casos notificados, pelos quais se responsabilizou com exclusividade.

0 resultado de todo esse esforço foi a significativa contribuição para a "economia" de seis anos de Campanha de Erradicação de Varíola no Estado de São Paulo, que, prevista para durar até 1979, encerrou-se em 1973, já que o último caso de varíola notificado no Estado foi em julho de 1970 e, no Brasil, em 15 de abril de 1971. Assim, em agosto de 1973, depois de dois anos do último caso, a ONU certificou a Erradicação da Varíola no Brasil.

Após avaliar os resultados da CEV e descrever e analisar a participação e atuação da enfermeira, constatamos que esta foi protagonista da campanha. Apesar de os relatórios principais da CEV registrarem que a Enfermagem só ficou responsável por treinamentos, pode-se verificar que, além disso, a Enfermagem criou vários programas e fez várias intervenções de natureza gerencial que possibilitaram o sucesso da campanha.

Vasconcelos ${ }^{15}$, no relatório final da CEV, relata que o sucesso desta se deu graças às atividades rigorosas de vigilância epidemiológica e de vacinação de manutenção de recém-nascidos, escolares, pessoas não vacinadas que não apresentavam as cicatrizes de vacinação, mas agora sabe-se que estes programas foram todos elaborados pelas enfermeiras da CEV.

Durante toda a Campanha, as estratégias utilizadas foram estritamente elaboradas pelas enfermeiras citadas. Porém, elas aparentemente não conferiram valor ao trabalho realizado durante o período, deixando registros em dados quantitativos, não lhes atribuindo julgamento adequado para realizar a avaliação do serviço prestado. Cuidaram de toda a logística, fizeram todo o planejamento, participaram ativamente da execução, mas se esqueceram da avaliação. Esse comportamento, característico da enfermeira formada para servir focada na atividade assistencial e na gerência de nível intermediário, pode explicar porque não se encontraram publicações sobre o assunto datadas daquela época.

Além do que foi descrito, as enfermeiras da CEV ainda participaram da Primeira Jornada de Vacinação do Estado de São Paulo, na aplicação de BCG intradérmico no município de Taboão da Serra e na atualização de conhecimentos científicos por meio de material informativo recebido pela CEV.

Por fim, chama-se atenção para o Museu de Saúde Pública Emílio Ribas (MUSPER), que está em reforma desde março de 2005 e que tem riqueza muito grande de documentação, perdendo-se sob a ação de pragas e efeitos do clima, pois está inadequadamente instalada, e, ainda, tem falta de funcionários especializados para catalogar e tratar o acervo. Como pesquisadoras, podemos garantir que há documentos ainda intocados dentro do acervo, onde foram encontrados, durante a presente pesquisa, curiosidades como fotografias, cartas de amor e dinheiro do século XIX dentro de livros e pastas, uma prova de que pouco foram manuseados e que há muito por descobrir e estudar sobre a História da Saúde Pública no Estado de São Paulo.

\section{Referências}

1. Marchinatti CRE, Dias IMAV. A produção científica sobre vacinação na literatura brasileira de enfermagem no período de 1973 à 1999. Esc Anna Nery Rev Enferm 2003 abr; 7(1): 57-68.

2. Veronesi R, Focaccia R. Tratado de Infectologia. São Paulo(SP): Atheneu; 1996. p. 520-24.

3. Lorraca LM, Carraro TE. 0 mundo das vacinas: caminhos (des) conhecidos. Cogitare Enferm jun/dez 2000; 5(2): 43-50.
4. Fernandes TM. Imunização antivariólica no século XIX no Brasil: inoculação, variolização, vacina e revacinação.Hist Cienc SaúdeManguinhos 2003; 10(supl 2): 461-74.

5. Museu de Saúde Pública Emílio Ribas-MUSPER. Secretaria Estadual de Saúde de São Paulo. A varíola no Brasil; 1968. Série CEV. caixa n ${ }^{\circ} 6$.

6. Ministério da Saúde (BR). Trinta anos de Programa de Imunização. Brasília (DF); 2004.

7. Coelho CP. Escola de Enfermagem Anna Nery: suas histórias e suas memórias. Rio de Janeiro (RJ): Cultura Médica; 1997. p.189. 
8. Chalhoub S. Cidade febril. São Paulo(SP): Companhia das Letras; 1996. p.114-19.

9. Teixeira LA, Almeida M. Os primórdios da vacina antivariólica em São Paulo: uma história pouco conhecida. Hist Cienc Saúde-Manguinhos 2003: 10(supl 2): 475-98.

10. Museu de Saúde Pública Emílio Ribas-MUSPER. Secretaria Estadual de Saúde de São Paulo. Relatório de atividades da CEV; 1970. Série CEV. caixa $n^{\circ} 4$.

11. Museu de Saúde Pública Emílio Ribas-MUSPER. Secretaria Estadual de Saúde de São Paulo. Vacinação antivariólica em massa da população do Estado de São Paulo: resultados e avaliação; 1971. Série CEV. caixa $n^{\circ} 01$.

12. Museu de Saúde Pública Emílio Ribas-MUSPER. Secretaria Estadual de Saúde de São Paulo. Trabalhos da CEV: enfermagem na CEV. Série CEV. caixa $n^{\circ} 9$.

13. Museu de Saúde Pública Emílio Ribas-MUSPER. Secretaria Estadual de Saúde de São Paulo. Rui Soares: resultados e avaliação; 1971. Série CEV. caixa ${ }^{\circ} 03$.

14. Museu de Saúde Pública Emílio Ribas-MUSPER. Secretaria Estadual de Saúde de São Paulo. Relatório final da CEV; 1974. Série CEV. caixa $n^{0} 05$.

\section{Agradecimentos}

Agradecemos aos pesquisadores e companheiros de dois anos de luta do Centro de Estudos e Pesquisas sobre História da Enfermagem. E, especialmente, a Jandira Lopes Oliveira, Rute Castro e José Fernando da Silva, funcionários do MUSPER.

\section{Notas}

aTrabalho de Conclusão de Curso de Graduação em Enfermagem da FACENF / UNISA no ano de 2005.

bO MUSPER foi criado por uma iniciativa do médico sanitarista Dr. José Alves dos Santos, na gestão do Secretário da Saúde Dr. Walter Leser, para preservar e divulgar a atuação do Dr. Emílio Marcondes Ribas, pioneiro da saúde pública paulistana. Foi instalado no antigo prédio do Desinfetório Central, construído em 1893, uma das mais antigas instituições da Saúde Pública paulista. 0 prédio foi tombado em 1984 pelo Condephaat, que o consagrou como Patrimônio Histórico do Estado. Em 1987, foram ampliadas as funções originais do Museu da Saúde, com a criação do Centro de Preservação à Memória da Saúde Pública, com a proposta de recuperar, preservar, sistematizar e divulgar os documentos que se reportam à memória histórica dos serviços estaduais de saúde em São Paulo. Em outubro de 2005, o Centro de Memória da Saúde - Museu da Saúde Pública Emílio Ribas foi incorporado ao Instituto de Saúde / CCTIES / SESSP, tendo como meta a preservação do patrimônio histórico e cultural da Saúde, a pesquisa, a promoção e a eqüidade no direito à informação e ao conhecimento em Saúde.

\section{Sobre as Autoras}

\section{Aildnize Geselli Santos}

Enfermeira formada pela FACENF / UNISA. Membro do Centro de Estudos e Pesquisa s sobre História da Enfermagem, na linha de pesquisa História da Administração em Enfermagem.

\section{Maria Cristina Sanna}

Doutora em Enfermagem e Pesquisadora Independente. Líder do Centro de Estudos e Pesquisas sobre História da Enfermagem. 